INTERNATIONAL JOURNAL OF

SYSTEMATIC BACTERIOLOGY

Vol. 20, No. 2 April 1970

pp. $185-189$

Copyright 1970, Iowa State University Press

\title{
THE TAXONOMY AND NOMENCLATURE OF ENTEROCOCCI
}

\author{
A. P. Kalina \\ State Institute of Medical Biological \\ Preparations Control "L. A. Tarassevich" \\ Moscow, USSR
}

ABSTRACT. Request for an Opinion from the Judicial Commission designating the type species of the genus Enterococcus Thiercelin

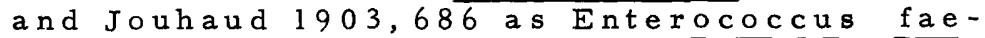
calis (Andrewes and Horder) Kalina 1968,11 .

In 1899 Thiercelin described the morphological and some biological properties of a new Gram-positive diplococcus. On account of its intestinal origin he called his organism "enterocoque." In 1903 Thiercelin and Jouhaud proposed the generic name "Enterococcus" with type species Enterococcus proteiformis.

In 1906 Andrewes and Horder, on the basis of ability of this organism to form short or, under certain conditions, long chains, renamed it "Streptococcus faecalis." In later classifications, the enterococci were included in the genus Streptococcus, together with hemolytic, greening, dairy and other streptococci.

On the basis of our investigations on the characteris tics of a large number of enterococci and abundant descriptions of enterococci given in the literature, we concluded (Kalina 1968) that such nomenclatural and taxonomic decision should be reconsidered.

Inclusion of enterococci in the genus Streptococcus is questionable because of their morphology. Our investiga tions indicate the main type of cell arrangement is in pairs - enterococci are diplococci. Even in preparations made from liquid cultures the most frequent disposition is in pairs. The proportion of short chains increased in old cultures and in media containing bile, especially whole bile. Hence, chain formation is a result of unfavorable environmental conditions and is not a normal physiological 
property. The enterococci are polymorphic; true streptococci are not.

Biological and cultural properties also distinguish the enterococci from species of the genus Streptococcus. They differ from streptococci by Sherman's tests and by many cultural peculiarities - the diffuse growth in broth, confluent growth on the surface of solid media, and others.

The antigenic structure of the enterococci separates them from the streptococci. Enterococci are included in group D of Lancefield's classification, but the disposition of antigens distinguishes them from streptococci. The group D antigen, according to Shattock and Smith 1963, Barber et al. 1966, and Kalin 1968, is found not in the cell-wa $\overline{l l}, \mathrm{as}$ in the A group of streptococci, but inside of the cell, on the surface of the protoplast. Fibrinolysin activity is typical for Group A streptococci, but has no value for the definition of pathogenity of enterococci (Wilson and Miles 1964, Kornilova 1959, Kalina 1968). We were not able to demonstrate production of hyaluronidase by pathogenic enterococci, although this property is characteristic of group $A$ and other streptococci.

There seem to be no morphological, biological, cultural or serological reasons for inclusion of enterococci in the genus Streptococcus. The enterococci constitute the particular genus Enterococcus Thiercelin et Jouhaud, tribe Streptococcaeae, family Lactobacillaceae.

The name Streptococcus proteiformis Thiercelin et Jouhaud 1903 has priority as the name of the type species of this genus, but has not been used subsequently by bacteriologists. The specific epithet "faecalis" (Andrewes and Horder) has been applied quite consistently. We are proposing that the generic name Enterococcus Thiercelin and Jouhaud be conserved with the type species $E$. faecalis (Andrewes and Horder) Kalina 1968, 11. The stable variants of Enterococcus faecalis are, as designated in Bergey's Manual (1957, 523, 524) as Streptococcus faecalis subsp. liquefaciens (Sternberg) Mattick 1947, 519 and S. faecalis subsp. zymogenes (McCallum and Hastings) Mattick 1947, 519.

The second species is Enterococcus faecium (OrlaJensen 1919) Kalina 1968, 13, Streptococcus durans Sherman and Wing 1937, 165 does not warrant independent species status based upon our own studies and in accordance with findings of Deibel (1964), Hartman, Reinbold and Saraswat (1966), and others. We include this microorganism in our 
proposed classification as Enterococcus faecium subsp. durans (Deibel, Lake and Niven) Ka lina 1968, 13.

In summary, we conclude that the genus Enterococcus Thiercelin and Jouhaud includes two species:

L. Enterococcus faecalis (Andrewes and Horder) Kalina 1968, 11 . subsp. Liquefaciens (Mattick)Ka lina 1968, 13. subsp. zymogenes (Mattick) Kalina 1968, 13.

2. Enterococcus faecium (Orla-Jensen) Kalina 1968, 13. subsp. durans (Deibel, Lake and Niven) Kalina $1968,13$.

We have not studied Streptococcus bovis Orla-Jensen 1919, 137 or Streptococcus equinus Andrewes and Horder 1906, 712 in detail, so we cannot determine their taxonomic position as we have no cultures. But, as shown by many investigators, these microorganisms must occupy a position intermediate between the genera Streptococcus and Enterococcus. On the one hand, they have an ecology and some morphological and cultural properties common to organisms of the genus Enterococcus; On the other hand, they are distinguished from the latter by some of Sherman's criteria. However, we are not able to propose any recommendations concerning these species.

We propose the following tentative key to species and subspecies of the genus Enterococcus:

I. Litmus milk reduced before curdling. 2, 3, 5-triphenyl tetraxolium chloride and potassium tellurite reduced. Sorbitol fermented.

A. Not beta-hemolytic

1. Gelatine not liquefied Enterococcus faecalis

2. Gelatin Liquefied Enterococcus faecalis var. liquefaciens

B. Beta-hemolytic. Gelatin liquefied or not liquefied Enterococcus faecalis var, zymogenes

II. Litmus milk not reduced before curdling. $2,3,5$ triphenyl tetraxolium chloride and potassium tellurite not reduced. Sorbitol not fermented.

A. Mannitol fermented, not beta-hemolytic Enterococcus faecium

B. Mannitol not fermented. Beta-hemolytic (more often) or not beta-hemolytic

Enterococcus faecium subsp. durans 
The Judicial Commission is requested to consider and approve the following recommendation, on the basis of the foregoing statements:

1. That the type species of the genus Enterococcus Thiercelin and Jouhaud 1903 be designated as Enterococcus faecalis (Andrewes and Horder) Ka lina 1968, 11 .

2. That the basionym of Enterococcus be designated as Streptococcus faecalis Andrewes and Horder and that Streptococcus proteiformis be rejected.

\section{REFERENCES}

Andrewes, F. W. and T. J. Horder 1960. A study of the streptococci pathogenic for man. Lancet $11: 708-713$, $775-782,852-855$.

Barber, C., P. Pleceas and E. Olinesco. 1966. Contribution a l'etude antigenique des streptocoques du Gruppe D. Lancefield. Pathol. Microbiol. 29:480-488.

Breed, R. S., E. G. D. Murray and N. R. Smith. 1957. Bergey's Manual of Determinative Bacteriology. The Williams and Wilkins Co., Baltimore. 7th ed. pp. 1 1894.

Deibel, R. H. 1964. The group D streptococci. Bact. Rev. 28:330-366.

D. E. Lake and C. F. Niven, Jr. 1963.

Physiology of the enterococci as related to their taxonomy. J. Bact. 86(6):1275-1282.

Hartman, P. A., G. W. Reinbold and D. S. Saraswat. 1966. Indicator organisms - a review. I. Taxonomy of the fecal streptococci. Int. J. Syst. Bact. 16: $197-221$.

Kalina, A. P. 1968. Biology and systematics of enterococci. Dissert. med. Sci. Microb. Ministry HLth, Mechnikov Inst. Serum Vaccine, Moscow. pp. 1-18.

Kornilova, N. M. 1959. Thesis. Leningrad.

Mattick, A. T. R. 1949. The lactic streptococci (including their antibiotic activity). Rep. 4th Int. Congr. Microbiol., Copenhagen. p. 519.

Shattock, P. M. F. and D. G. Smith. 1963. The location of the Group D antigen in a strain of Streptococcus faecalis var. Liquefaciens. Proc. Soc. gen. Microbiol. in J. gen. Microbiol. $\underline{31}$ (1):IV.

Thiercelin, E. 1899. Sur un diplocoque saprophyte de l'intestin susceptible de devenir pathogene. C. R. Soc. Biol.

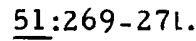


and L. Jouhaud. 1903. Reproduction de l'enterocoque: Taches centrales; granulations peripheriquee et microblastes. C. R. Soc. Biol. 55:686-688.

Wilson, G. S. and A. A. Miles. 1964. Topley and Wilson's principles of Bacteriology and Immunity. 5th ed. Baltimore. pp. 1-1191. 